\title{
TRAP EFFICIENCY OF ALMATTI RESERVOIR IN KRISHNA BASIN - A CASE STUDY
}

\author{
M.Visweswararao ${ }^{1}$, Dr G K Viswandh ${ }^{2}$
}

\begin{abstract}
In this paper an attempt has been made to study the sedimentation aspects of this reservoir and to evolve the sedimentation rates and trap efficiency of Almatti reservoir. When a dam is constructed on a river to store water, sediments transported by the water flow are also stored and reservoir capacity is gradually reduced by sediment accumulation. Prediction of sediment distribution in reservoirs is an important issue for dam designers to determine the reservoir active storage capacity, outlet sill elevation, dam stability, recreational facilities, and back water conditions. In this study, the sediment deposition in Almatti on Krishna river in Karnataka is studied. The sediment rates are worked out considering the hydrographic surveys conducted by State of Karnataka and the same are compared with the hydrometrical observations conducted by CWC at various G\&D stations in Krishna river. The trap efficiency is also estimated considering the observations at the gauging stations. It is observed that the hydrographic and hydrometry observations fairly tally. The trap efficiency worked out as $84.3 \%$ a bit different from Brunes trap efficiency median curve. The trap efficiency more or less converges to the lower envelop curve.

Keywords: Sediment load, trap efficiency,FRL,storage capacity,hydrographic surveys
\end{abstract}

\section{INTRODUCTION}

Sedimentation processes in reservoirs and lakes have been reported by many authors, including Mahmood [1], Hotchkiss and Parker [2], Fan and Morris [3], Sloff [4], De Cesare et al. [5], among others. The sedimentation process in reservoirs, caused by impounding a river, results in the increase of the cross-sections available for the flow, subsequently decreasing the flow velocity. Thus, the sediment transport capacity decreases.

This causes the deposition of sediments, the consequences of which depend on the size, shape and location of the deposits.

The forecast of sediment distribution in reservoirs may be prepared using empirical and theoretical methods. Theoretical approaches to forecasting water reservoirs' silting are mathematical methods that can be divided into analytical and numerical ones. Irrespective of the type of theoretical model used, it is necessary to calibrate or verify the results of calculations. Such opportunity is created by the field test results. Regarding empirical methods they are based on data of some reservoirs in the USA which may not be applicable to the Indian conditions. Hence it is nessary to develop trap efficiency from the observed data and to adopt the revised empirical relations to suit that particular reservoir or set of reservoirs situated in India. The actual observed sediment loads and hydrographic survey throw better light on trap efficiency and often form the basis for easy empirical methods, the use of which

\footnotetext{
${ }^{1}$ Professor in Civil Engineering Department, Malla Reddy Institute of Technology, Mysammaguda, Kompalli, Secundrabad

${ }^{2}$ Professor in Civil Engineering Department, OSD to Vice Chancelor,JNTUH,Hyderabad
} 
does not require much effort. The results allow for the assessment of the approximate course of the analyzed phenomenon or process.

\section{LITERATURE SURVEY}

The Total sediment load can be estimated from hydrometric observations and establishing the sediment discharge relations.

H.G. hlimemann[6] (1975)has estimated trap efficiency of three reservoirs based on detention time and particle size. In this theory also in direct variables causing trap efficiency are used but in the present study actual observed data is used.

G. Venkatesan and Jean poison[7](2000) have estimated the trap efficiency of small reservoirs bydeveloping theoretical models based on over flow rate and concluded that these models can be used for estimation of trap efficiency of small reservoirs. As Almatti is a major reservoir this theory is not applicable to Almatti.

Abol Fazi[8](2006) has estimated the sediment load in to the Karaj Dam using hydrometry observations of upstream and downstream and compared them with the hydrographical survey of the reservoir and concluded that the results are compatible with a regression coefficient of 0.97. These observations pertain to a reservoir in IRAn and the conclusions may not be suitable for Indian conditions. Therefore it is necessary to study the hydrometrical observations and hydrographic observations of Almatti to arrive at suitable conclusions.

The rate of sedimentation and useful reservoir life have also been estimated by Vaibhav and others[9] (2008)adopting trap efficiency approach. In this determination also actual observed data of hydrographic survey is not available.

Vaibhav Garg[10] (2009)and others have developed artificial neural network models for estimation of sediment load. The observations of hydrometry vary over time and discharge and differ very signjficantly for different discharges. Therefore this method was developed . It was stated that Hydrographic observations are costly for small reservoirs and hence it was suggested that for small reservoirs this method can be used in the absence of hydrographic surveys. As almatti reservoir is a major reservoir and hydrographic observations are available this study may not be suitable for Almatti.

Jaypak and Paul ely [11](2010)have estimated the trap efficiency by hydrological modelling system using HEC-HMS based on storm rain falls and retention periods. These studies are based on other indirect parameters effecting trap efficiency but not direct observations.

Trap efficiency was also estimated for reservoirs in tropical settings for Burdekin reservoir in Australia by Lewis.S. E.[10] (2013)from observed data and compared the same with the results from Brunes and churcils methods. In this study also the trap efficiency estimated from observed data and compared with Brunes curves.

\section{METHODOLOGY FOR THE PRESENT STUDY:}

Almatti reservoir is on Krishna river in Karnataka state. It is one of the biggest reservoirs in Krishna and has to contribute huge quantities of flow to the down stream states of Telengana and Andhra Pradesh. Therefore it is important to study this reservoir for sedimentation and other operational aspects so as ensure that the system down below functions satisfactorily as per the awards and the down stream demand will be met at the desired levels. The salient features of Almatti reservoir are given in Table 1.

Table 1 Salient Features of Almatti reservoir

\begin{tabular}{|l|l|l|}
\hline SL.NO & Particulars & Details \\
\hline 1 & Type of reservoir & Major \\
\hline
\end{tabular}




\begin{tabular}{|l|l|l|}
\hline 2 & Purpose of reservoir & Irrigation and power \\
\hline 3 & Year of impoundment to FRL & 2003 \\
\hline 4 & Silt rate assumed for design & $1.00 \mathrm{Acft} / \mathrm{Sq}$. Mile/year \\
\hline 5 & Catchment area & $35926 \mathrm{Sq}$. Miles \\
\hline 6 & Annual rain fall in mm & 500 \\
\hline 7 & Lowest bed level & $488.95 \mathrm{~m}$ \\
\hline 8 & Crest level & $509.016 \mathrm{~m}$ \\
\hline 9 & Dead storage level(MDDL) & $506.87 \mathrm{~m}$ \\
\hline 10 & Sill of river sluice & $495.306 \mathrm{~m}$ \\
\hline 11 & FRL & $519.6 \mathrm{~m}$ \\
\hline 12 & MWL & $519.80 \mathrm{~m}$ \\
\hline 13 & Maximum water spread & $181 \mathrm{Sq} . \mathrm{Km}$ \\
\hline 14 & FRL for stage 3 & $524.256 \mathrm{~m}$ \\
\hline 15 & Maximum water spread at 524.256 & $487.87 \mathrm{Sq} . \mathrm{Km}$ \\
\hline 16 & Height of dam from lowest B.L & $40.3 \mathrm{~m}$ \\
\hline 17 & Design flood intensity & $31007 \mathrm{Cumecs}$ \\
\hline 18 & Top width of dam & $7.5 \mathrm{~m}$ \\
\hline 19 & No. And size of spill way gates & 26 nos of $15 * 10.584$ m(radial) \\
\hline 20 & No. And size of gates in stage 3 & 26 no.s of $15^{*} 15.24$ m(radial) \\
\hline
\end{tabular}

In this paper an attempt has been made to study the sedimentation aspects of this reservoir and to evolve the sedimentation rates and trap efficiency of Almatti reservoir.The total sediment loads observed at the hydrometry stations on Krishna upstream of Almatti reservoir are transferred to Almatti considering the rate of sedimentation.These are then compared with the hydrographic surveys conducted and the trap efficiency is worked out.

Suspended sediment observations at various stations of Krishna basin are being observed by CWC. Galgagi is situated just upstream of Almatti on main Krishna river. Similarly Bagalkot station is situated at the end of Ghataprabha a distributary of Krishna which joins the main Krishna just upstream of Almatti. The silt loads from these two stations are considered and the average load that is being measured at these stations is worked out. This sediment will flow to Almatti. The bed load is considered as $20 \%$ in addition to the suspended load. The consolidated density of the sediment is considered as $1.4 \mathrm{t} / \mathrm{cum}$. This is used to convert the sediment load in tons into sediment volume.

The basic rate of silt load i.e without any effect of reservoirs intervention is worked out from sediment observation stati ons at Krishna Agraharam, Huvanahegdi on main Krishna and yadgir on bhima stations as the catchment is not effected by the reservoirs except Jurala the trap efficiency of which is very low. This rate is then applied to the free catchment between Galgali, Bagalkot and Almatti and added to the sediment loads observed at Galgali and Bagalkot to arrive at the total sediment load flowing to Almatti reservoir.

The hydrographic survey was conducted by state of Karnataka in 2009 and these studies are used to estimate the sediment trapped in Almatti. The reservoir was completed upto crest in 1994 and filled upto MDDL+506.87. The reservoir was filled up to crest from 1998 on wards.The level of 515 is maintained in 2001,2002 and water is stored up to FRL in 2003.The reservoir is being operated with FRL +519.6 m from 2003 onwards. The revised area, capacities corresponding to the reservoir elevation are given in Table 2. The graphical representation of the elevation vs area and capacity for original and revised as per survey 2009 are given in fig. $1 \&$ fig 2 respectively. 
TABLE 2

Area-elevation-capacity table of Almatti reservoir(Original and 2009 survey)

elevation

$$
\begin{array}{lll} 
& \multicolumn{2}{c}{\text { revised(2009 }} \\
\text { original } & & \text { survey) } \\
\text { area capacity } & \text { area capacity }
\end{array}
$$

$\begin{array}{llllll}500 & 25.82 & 157.34 & 22.74 & 92.7 \\ 503.5 & 41.31 & 259.6 & 40.31 & 203.03 & \\ 504 & 51.23 & 304 & 50.86 & 225.77 & \\ 504.3 & 54.34 & 318 & 54.31 & 241.54 & \\ 504.6 & 57.9 & 335 & 57.1 & 258.25 & \\ 504.9 & 61.2 & 353 & 59.97 & 275.81 & \\ 505.2 & 64.7 & 373 & 63.37 & 294.31 & \\ 505.5 & 68.3 & 394 & 66.65 & 313.81 & \\ 505.8 & 71.9 & 414 & 70.9 & 334.43 & \\ 506.1 & 75.7 & 438 & 75.15 & 356.34 & \\ 506.4 & 80 & 460 & 79.15 & 379.48 & \\ 506.7 & 83.06 & 485 & 82.61 & 403.74 & \\ 506.87 & 85.33 & 500 & 84.43 & 417.94 & \text { MDDL } \\ 507 & 87.33 & 510 & 86.08 & 429.03 & \\ 507.3 & 93.33 & 538 & 91.67 & 455.68 & \\ 507.6 & 97.6 & 567 & 95.76 & 483.79 & \end{array}$

$\begin{array}{lllll}507.9 & 102.66 & 600 & 99.46 & 513.08\end{array}$

$\begin{array}{lllll}508.2 & 106.8 & 628 & 103.96 & 543.59\end{array}$

$\begin{array}{lllll}508.5 & 112 & 660 & 108.4 & 575.44\end{array}$

$\begin{array}{llllll}508.8 & 117.33 & 697 & 113.39 & 608.7\end{array}$

$\begin{array}{llllll}509.1 & 121.6 & 730 & 118.27 & 643.45\end{array}$

$\begin{array}{lllll}509.4 & 126.66 & 768 & 123.12 & 679.66\end{array}$

$\begin{array}{llllll}509.7 & 132 & 808 & 128.14 & 717.34\end{array}$

$\begin{array}{llllll}510 & 137.33 & 848 & 133.21 & 756.54\end{array}$

$\begin{array}{llllll}510.3 & 142.66 & 888 & 137.73 & 797.18\end{array}$

$\begin{array}{llllll}510.6 & 148 & 932 & 142.54 & 839.22\end{array}$

$\begin{array}{llllll}510.9 & 153.33 & 976 & 147.25 & 882.69\end{array}$

$\begin{array}{lllll}511.2 & 160 & 1020 & 153.05 & 927.73\end{array}$

$\begin{array}{lllll}511.5 & 165.33 & 1070 & 159.64 & 974.63\end{array}$

$\begin{array}{lllll}511.8 & 172 & 1120 & 166.31 & 1023.52\end{array}$

$\begin{array}{lllll}512.1 & 178.66 & 1174 & 172.97 & 1074.41\end{array}$

$\begin{array}{lllll}512.4 & 184 & 1228 & 179.64 & 1127.3\end{array}$

$\begin{array}{lllll}512.7 & 189.33 & 1283 & 186.31 & 1182.19\end{array}$

$\begin{array}{llllll}513 & 194.66 & 1342 & 192.97 & 1239.07\end{array}$

$\begin{array}{lllll}513.3 & 201.06 & 1400 & 199.45 & 1297.94\end{array}$

$\begin{array}{llllll}513.6 & 206 & 1463 & 204.86 & 1358.58\end{array}$

$\begin{array}{lllll}513.9 & 215.33 & 1524 & 211.89 & 1421.09\end{array}$

$\begin{array}{lllll}514.2 & 226.66 & 1595 & 221.25 & 1486.05\end{array}$

$\begin{array}{lllll}514.5 & 238 & 1660 & 233.89 & 1554.32\end{array}$ 


$\begin{array}{lllll}514.8 & 249.33 & 1735 & 247.94 & 1626.58 \\ 515.1 & 261.33 & 1812 & 261.53 & 1702.99 \\ 515.4 & 274.66 & 1896 & 275.32 & 1783.51 \\ 515.7 & 287.33 & 1980 & 288.41 & 1868.06 \\ 516 & 301.33 & 2068 & 301.53 & 1956.55 \\ 516.3 & 316 & 2155 & 314.86 & 2049 \\ 516.6 & 329.33 & 2255 & 327.28 & 2145.31 \\ 516.9 & 344 & 2356 & 340.65 & 2245.49 \\ 517.2 & 360 & 2460 & 355.56 & 2349.92 \\ 517.5 & 375.33 & 2574 & 371.35 & 2458.95 \\ 517.8 & 390 & 2688 & 387.35 & 2572.74 \\ 518.1 & 407.33 & 2810 & 404.72 & 2691.54 \\ 518.4 & 425.33 & 2930 & 421.8 & 2815.51 \\ 518.7 & 441.33 & 3065 & 438.01 & 2944.48 \\ 519 & 457.33 & 3200 & 454.93 & 3078.41 \\ 519.3 & 476 & 3340 & 471.35 & 3217.35 \\ 519.6 & 487.87 & 3486 & 488.26 & 3361.28 \\ 519.9 & 509.37 & 3635 & 504.71 & 3510.22 \\ 520.2 & 522.66 & 3790 & 518.87 & 3663.75 \\ 520.5 & 537.33 & 3950 & 533.1 & 3821.55 \\ 520.8 & 550.66 & 5015 & 546.86 & 3983.54\end{array}$

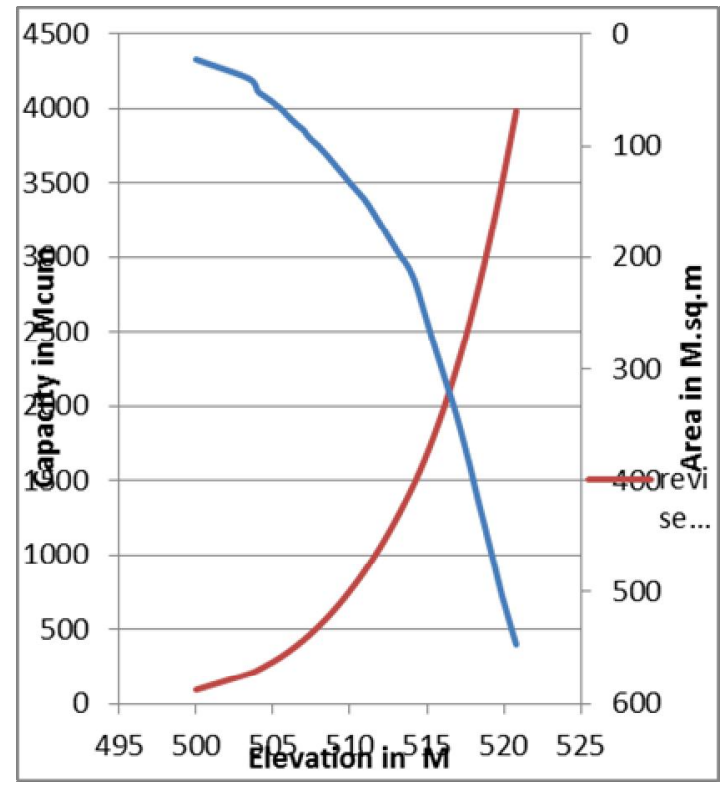

FIG1 : ELEVATION VS AREA, CAPACITY OF ALMATTI RESERVOIR(ORIGINAL) 
From table 2 it could be seen that the revised capacity at FRL i.e $519.60 \mathrm{~m}$ is 3361.28

Mcum as against the original capacity of

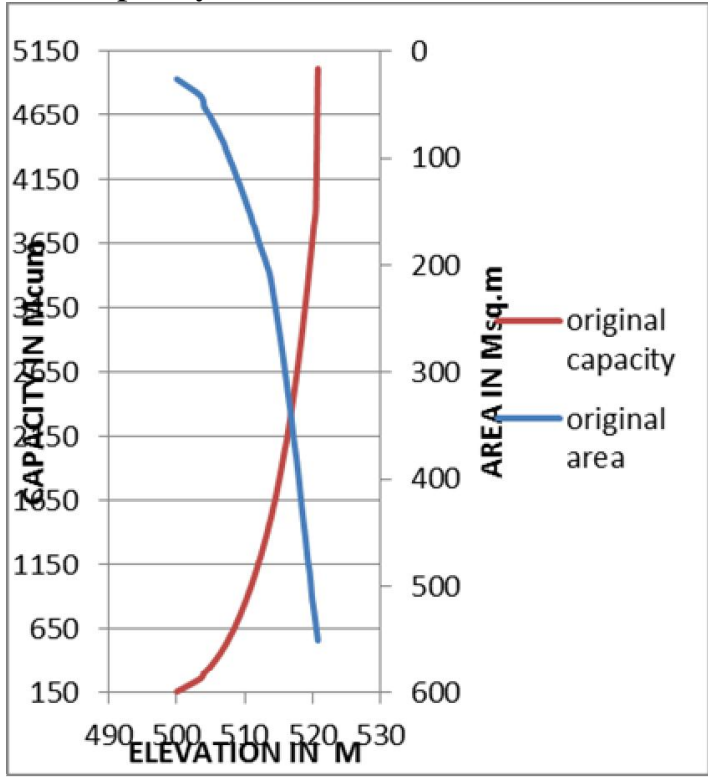

FIG2 : ELEVATION VS AREA, CAPACITY OF ALMATTI RESERVOIR(REVISED)

3486.00Mcum . Therefore the sediment trapped in Almatti reservoir for the period 1994 to 2009 is $3486-3361.28=124.72$ Mcum.

The sediment volumes trapped and the total sediment loads are considered and the trap efficiency is worked out.

\section{SEDIMENT LOAD AND TRAP EFFICIENCY CALCULATIONS IN ALMATTI RESERVOIR}

4.1. Total sediment load at Almatti:There are two hydrometric stations up stream of Almatti one at Galgali on main Krishna and another on Ghataprabha at BagalKot. All the sediment that flows from these measuring sites and the sediment generated in the intermediate catchment between Galgali \& Bagalkot to Almatti will flow in to the Almatti reservoir. Thus the total silt load that will be deposited in Almatti on an average per year and the rate of sedimentation in to Almatti is worked out from the observed data as shown below

\subsection{Sediment load from upstream gauge sites:}

Average silt load @ Galgali = 4254378 Metric Tonnes (as per observed data at Galgali for 1976-77 to 1994-95)

Density adopted $=1.40$ Metric Tonnes (As per CWC guidelines)

Average silt in Cum $=4254378 / 1.40=\mathbf{3 0 3 8 8 4 1} \mathbf{C u m}$

Silt load including bed load at $20 \%=3038841 * 1.20=3646609$ cum

Average Silt load @ Bagalkot=1646629 Metric Tonnes (As per observed data at Bagalkot for 1976-77 to 1994-95)

Density adopted $=1.40$ Metric Tonnes/ Cum 
Average silt in Cum $=1646629 / 1.40=\mathbf{1 1 7 6 1 6 3}$ CumSilt load including bed load at $20 \%=$ $1176163 * 1.20=1411396 \mathrm{cum}$

Total from two stations per year $=3646609+1411396=5058005$ Cum.

\subsection{Free catchment area :}

a) Catchment area upto Almatti

b) Catchment area upto Galgali

c) Catchment area upto Bagalkot

$$
\begin{aligned}
& =35926 \mathrm{sq} . \mathrm{km} . \\
& =22559 \mathrm{sq}, \mathrm{km} \\
& =8609 \mathrm{sq} . \mathrm{km}
\end{aligned}
$$

The Catchment area between Almatti, Galgali \& Bagalkot

$$
[\mathrm{a}-(\mathrm{b}+\mathrm{c})] \quad=35926-31168=\mathbf{4 7 5 8} \mathrm{sq} \cdot \mathrm{km}
$$

\section{4 .Rate of siltation from un intercepted catchment :}

Rate of sedimentation from unintercepted catchment was worked out from the sediment observation stations at Krishna Agraharam, Huvanahegdi on main Krishna and yadgir on bhima stations as this catchment is not effected by the reservoirs except Jurala . The sediment that flows in to jurala is sediment loads from huvanahegdi and yadgir as well as the sediment generated from unintercepted catchment between huvanahegdi, yadgir and jurala.Out of this silt load some portion is trapped and the rest goes down. This sediment flowing down and the sediment generated from jurala to Krishna agraharam should reach Krishna agraharam. to get the total sediment load reaching Krishna Agraharam.

The average sediment load from huvanahegdi = 12867091 MT(CWC data from 1976-1994)

The average sediment load from Yadgir $=14424770$ MT(CWC data from 1976-1994)

Total load from both stations considering bed load as $20 \%$ and density as 1.4= $(12867091+14424770) * 1.2 / 1.4=23393024$ Cum

The average sediment load from Krishnaagraharam $=22697669$ MT(CWC data from 19761994)

Total load from Krishna Araharam considering bed load as $20 \%$ and density as $1.4=$

$22697669 * 1.2 / 1.4=19455145$

Free Catchment area between Jurala and huvanahedgi and yadgir=129590(jurala)55150 (huvanahedgi) -69863 (yadgir) $=4577$ sq. Km

Free catchment from jurala to Kagraharam $=132920$ (kagraharam)- $129590=3330$ Sq. Km

The trap efficiency as per Brunes curve is $45 \%$ (lower envelope)

Let $\mathrm{x}$ be the basic rate. Then

(Sediment from huvahegdi and yadgir $+4577 * x) * 0.55+3330 * x=$ sediment at Krishna agraharam

$(23393024+4577 * x) * 0.55+3330 * x=19455145$ Cum 
Solving for $\mathrm{x}$, $\mathrm{x}$ works out to $1126 \mathrm{cum} / \mathrm{sq} . \mathrm{km} / \mathrm{year}$. This equals to $2.486 \mathrm{Acft} / \mathrm{sq} . \mathrm{mile} / \mathrm{year}$

\section{5. silt load from Free catchment between almatti and Galgali\&Bagalkot:}

The intervening catchment between Galgali, Bagalkot and Almatti $=4758$ Sq. Km

Silt- load generated from free catchment $=4758 * 1126=5357508$ Cum including bed load for one year..

\subsection{Total silt load at almatti :}

The total sediment load per year works out to works out to $5058005+5357508=10415513$ Cum or 10.42 Mcum.

Over all Rate of silt up to Almatti $=10.42 * 1000000 / 35926=$ $299 \mathrm{Cum} / \mathrm{sq} . \mathrm{km}$

(or) 0.621 acre-feet / sq. mile per year.

\subsection{Sediment load by hydrographic survey:}

The hydrographic survey was conducted by the state of Karnataka in 2009 in Almatti reservoir using DGPS,Digital echo sounder,total station, Auto level and various soft wares. The study indicated that the total silt deposited in Almatti at FRL of $519.6 \mathrm{~m}$ is 124.72 Mcum.

The impounding of Almatti started in 1994. Water was stored up to a level of $506.87 \mathrm{~m}$ during this year. From 1998 crest level is maintained.From 2001-02 a level of 515 was maintained for two years. Thereafter from 2003-04 on wards the FRL of 519.6 m is being maintained every year.

\subsection{Trap efficiency:}

The trap efficiency is worked out as below.

The silt generated per year $=10.42$ Mcum

The trap efficiency adopting Brunes lower envelope curve is worked out for the period when the reservoir was not filled up to FRL and the trap efficiency after the full impoundment is worked out.

The trap efficiency at $506.87=0.70$

The trap efficiency at crest i.e at 509.016 $=0.77$

The trap efficiency at $515=0.90$

$10.42 * 0.70 * 4+10.42 * 3 * 0.77+10.42 * 0.90 * 2+10.42 * x * 6=124.72$ where $\mathrm{x}$ is trap efficiency of almatti after full storage upto FRL i.e $519.600 \mathrm{~m}$

Solving for $\mathrm{x}$ we get $\quad 0.843$

Therefore considering FRL of $519.6 \mathrm{~m}$ the trap efficiency will be $84.3 \%$. The rate of siltation is $8.7868 \mathrm{Mcum} /$ year or $0.310 \mathrm{TMC}$ per year which is less than $1 \mathrm{TMC} /$ year indicating this reservoir will satisfactorily function for its entire life as the capacity at FRL is 123 TMC. It is proposed to increase FRL to $524.256 \mathrm{~m}$. Then the sediment trapped will increase 


\section{CONCLUSIONS\&FUTURE SCOPE:}

From the above calculations it could be seen that the rate of silt per year per sq. Km catchment area area up to Almatti worked out to $299 \mathrm{Mcum} / \mathrm{Sq} . \mathrm{KM} / \mathrm{year}$ or 0.621 Acft/sq.Mile/year. This is less than the load adopted for design of Almatti reservoir . thus the reservoir will function satisfactorily to meet its planned demands and sedimentation is not going to reduce the life of the reservoir. The total silt load per one year on an average worked out to 8.7868 Mcum or $0.31 \mathrm{TMC} /$ year which when compared to the live storage of about 120 TMC indicate that the useful reservoir life will not get effected and the benefits will be available for the entire planned period and beyond.The Trap efficiency of Almatti reservoir worked out to $84.3 \%$. This is slightly less than the trap efficiency observed by median cyurve of Brune and indicates that it more or less converges to lower envelope curve. This trap efficiency may be adopted for Almatti foy any studies based on the total sediment load generated and measured in Krishna river. These trap efficiencies may be checked with future hydrographic surveys and analysed for any change in trap efficiency.

\section{REFERENCES}

[1]. Mahmood, K. Reservoir Sedimentation: Impact, Extent and Mitigation; Technical Paper No. 71; The World Bank: Washington, DC, USA, 1987.

[2]. Hotchkiss, R.H.; Parker, G. Shock fitting of aggradational profiles due to backwater. J. Hydraul. Eng.1991, 117, 1129-1144.

[3]. Fan, J.; Morris, G. Reservoir sedimentation. I: Delta and density current deposits. J. Hydraul. Eng. ASCE 1992, 118, 354-369.

[4]. Sloff, C.J. Sedimentation in Reservoirs. Ph.D. Thesis, Technical University of Delft, Delft,The Netherlands, 15 April 1997.

[5]. De Cesare, G.; Schleiss, A.; Hermann, F. Impact of Turbidity Currents on Reservoir Sedimentation.J. Hydraul. Eng. ASCE 2001, 127, 6-16.

[6]. Ramesh. D. L,Hlinemann.H.G,controlling reservoir trap efficiency,1975, US Department,ASAE in 9/75(16)

[7]. Gert venkatesan,Jean Poeson,estimating trap efficiency of small reservoirs and ponds methods and implications for assessment of sediment yield,progress in geopraphy,June 2000,vol.24. no.2,p.219-251

[8]. Abolfazi, Moseadi,Estination of sediment volume in Karaj Dam Reservoir(iran) by hydro metry method and a comparision with hydrograph method,Lake and Management,9/2006,22(3)-233-239(3)

[9]. Vaibhav garg and Vinayakan,estimation of useful life of a reservoir using sediment trap efficiency, Journal of spatial hydrology,01/2008,8(2)-1-14(8)

[10]. Vinayakan \& Vaibhav garg,Reservoir sediment estimation using artificial neural net work, Journal of hydrological engineering 9/2009,14(9),1035-40(7)

[11]. Jaypak and Paulely,Assesment of reservoir trap efficiency methods using the hydrological modelling system(HEC-HMS)for the upper north bosque river water shed in texas,2010,2 $2^{\text {nd }}$ joint federal interagency conference, Lasvegas,june 27-july 1,2010

[12]. Lewis.S.E, calculating sediment trap efficiency for reservoirs in tropical settings- a case study from Burdekin reservoir, Water resources research, 2013,Vol 49, 1017-29-doi 10.1002/Wrc20117

[13]. I S 12182-1987, Guidelines for determination of effects of sedimentation in planning and performance of reservoirs , UDC 627.81, 627.8.034.7

[14]. CWC year books on sedimentationobservations for Krishna river for the period 1976-1994

[15]. Hydrographic survey of Almatti and hippargi reservoirs by Government Of Karnataka,2009 